\title{
Optimization of Overcast Stripping Technology Parameters Based on Discrete Event System Simulation
}

\author{
Zhang Zhao, ${ }^{1}$ Ruixin Zhang, ${ }^{2}$ Jiandong Sun $\mathbb{D D}^{2,3}$ and Shuaikang $\mathrm{Lv}^{1}$ \\ ${ }^{1}$ School of Energy and Mining Engineering, China University of Mining and Technology, Beijing 100083, China \\ ${ }^{2}$ North China Institute of Science and Technology, Hebei 065201, China \\ ${ }^{3}$ State Key Laboratory of Coal Resources and Safe Mining, China University of Mining and Technology, Beijing 100083, China
}

Correspondence should be addressed to Jiandong Sun; sjd_xx@126.com

Received 6 November 2021; Revised 30 December 2021; Accepted 12 January 2022; Published 1 February 2022

Academic Editor: Manoj Khandelwal

Copyright ( $\odot 2022$ Zhang Zhao et al. This is an open access article distributed under the Creative Commons Attribution License, which permits unrestricted use, distribution, and reproduction in any medium, provided the original work is properly cited.

In the process of open-pit mining, the system parameters determine the economic benefit and production efficiency of the mine. Conventional optimization involves building a system model for the process parameters. However, complex large-scale systems such as open-pit mining are difficult to model, resulting in a failure to obtain effective solutions. This paper describes a system simulation method for the process parameters involved in open-pit mining. The nature and interaction of each component of the system are analyzed in detail, and the logical flow of each layer of the system is determined. Taking the basic operational linkages of the equipment as the system drivers, we obtained the operational flow of dragline information. The barycentric circular projection method is used to simplify the control logic of the system, and a system storage state model is constructed to identify dynamic changes in the system and obtain the operation parameters of the dragline. A discrete event system is used for quantitative modeling, and the event step method is employed to advance the simulation process and obtain decision information. Finally, simulations are performed using various system parameters. The simulation results show that the maximum efficiency is achieved when the dragline height is $\sim 13 \mathrm{~m}$, giving a capacity of $4276.52 \mathrm{~m}^{3} / \mathrm{h}$. Error analysis indicates that the modeling error is minimized using a simulation correction coefficient of $\alpha=0.94$.

\section{Introduction}

Open-pit mining is the main means of extracting coal resources in the United States, Australia, and many other developed countries. It has been the focus of research on coal mining by researchers worldwide. In recent years, researchers around the world have made a lot of research achievements in the optimization of open-pit mining technology, open-pit mining production planning, and so on. In terms of process optimization of open-pit mining, $\mathrm{Ma}$ et al. [1] and Rui [2] proposed 3D visualization mining process optimization technology mainly supported by 3D laser scanning technology, which improved the informatization and intelligence degree of open-pit mining. Song et al. [3] made a systematic optimization and classification study on the green mining process of open-pit coal mine by constructing a reasonable matching relationship model of all links of the process system. Zheng [4] proposed a comprehensive process system optimization method under rigid process constraints in view of the complex geological conditions of open-pit coal mines. In terms of the optimization of open-pit process parameters, Zhao et al. [5] and $\mathrm{Ma}$ et al. [6] established the functional relationship between the height of cast blasting steps, the thickness of raw coal, and the production capacity of the dragline and optimized and established the process parameters of cast blasting and dragline stripping technology. Xiao et al. $[7,8]$ proposed the calculation method of the deformation time and operation cycle of the dragline and established the relationship model between the production efficiency of the dragline and the height and width of the operation platform. Liu [9] proposed three feasible dumping operation modes of dragline and analyzed and evaluated each operation mode according to operation steps, operation parameters, and applicable 
conditions. For the global optimization of complex systems, significant breakthroughs have been made in the military and medical fields. Pervaiz et al. [10], Bangyal et al. [11, 12], and others have adopted particle swarm optimization, lowdifference sequence algorithms, improved bat algorithms (IBA), and other advanced algorithms to improve the detection accuracy of medical diseases and solve the global optimization problems of complex systems. Such methods can be mapped to the optimization of open-pit mine systems.

In terms of mine production planning, Sepulveda et al. [13], Blom et al. [14], and other scholars have developed models that maximize the expected profit of open-pit mines using metaheuristics and simulation tools. For production scheduling, Rezakhah and Newman [15] established the graph structure of the maximum flow in multiple periods and used a genetic algorithm to control the flow within each arc to generate an effective production plan. Open-pit mining is a complex system, and the basic units of the system structure change in time and space according to the mode of the mining action. The characteristics of open-pit stopes are clearly affected by dynamic changes in geological conditions, and open-pit processes involve various modes of cooperation and coupled parameters. Therefore, open-pit mining systems are very difficult to optimize $[16,17]$.

In view of the above problems, a series of operational optimization methods have been introduced, such as planning theory, graph theory, and queuing theory [18]. The aim of these methods is to approximate various engineering problems so as to construct model forms that can be readily solved, such as linear algebra, linear differential, and linear difference equations. However, there is always a contradiction between the accuracy of the model and the effectiveness of the method, and approximations may lead to solutions that are far from the real solution. Additionally, the real system structure, parameters, and characteristics are mostly nonlinear, described by variable coefficients and variable-structure partial differential equations, for which there is a lack of general and accurate analytical methods. When the system cannot be solved by establishing a mathematical model, it is necessary to describe the evolution of the system and perform numerical simulations, so as to obtain a generalized model that is closer to the actual situation. Quantitative analysis can then be performed through simulation experiments to obtain more accurate solutions $[19,20]$.

Taking the dragline stripping technology used in Heidaigou open-pit mine, Inner Mongolia, China, as an example, we simulated the efficiency under different flat plate heights and obtained the optimized precise overcast stripping system. The results of this study can be used to improve the operational efficiency and economic benefit of dragline stripping in open-pit mines, and lay the foundation for further application and promotion of dragline stripping technology. This study also provides a new idea for the optimization of open-pit mining processes.

\section{Engineering Background}

In the Heidaigou open-pit mine, Inner Mongolia, China, the rock ( $\sim 40 \mathrm{~m}$ thick) above the roof of the coal seam is stripped by blast casting, overcast stripping, and single-bucket truck comprehensive mining. During the dragline operation in the overcast stripping system, a bulldozer and a single-bucket truck drive to the top of the blasted stockpile and discharge the materials from all parts of the working face to the dump in turn (as shown in Figure 1). The designed production capacity of the dragline is 25 million $\mathrm{m}^{3} / \mathrm{a}$, but the actual operation volume is less than 17 million $\mathrm{m}^{3} / \mathrm{a}$. The overcast stripping system needs to be equipped with an additional single-bucket-truck-assisted stripping volume of nearly 13 million $\mathrm{m}^{3} / \mathrm{a}$. The overcast stripping cost of the dragline is about 5 yuan $/ \mathrm{m}^{3}$ lower than that of the single-bucket-truck process. Therefore, if the operational efficiency of the dragline equipment could be improved by optimizing the parameters of the dragline working surface, the operational capacity of the equipment would be improved, and the overall operating cost of the system would be greatly reduced.

In Figure 1, the loess area indicates that the loess in the stope of the open-pit mine is stripped by the single-bucket truck. The upper rock area shows the open-pit stope rock being stripped by a single-bucket truck, and the lower rock area shows the stope rock of the open-pit mine being stripped by a single-bucket truck assisted by a dragline. Blast casting refers to the material pile formed after rock step blasting. The dump area of the dragline creates the mound. $H_{1}$ represents the step height of the single-bucket truck operation area, $\mathrm{H}_{2}$ represents the height of the cast blasting step, and $\mathrm{H}_{3}$ represents the height of the coal seam step.

There are many parameters in the overcast stripping system, among which the height of the flat plate is the most critical. As the flatbed height increases, the overall operating efficiency of the overcast stripping system will be affected as shown in Figure 2.

As can be seen from Figure 2, a change in the standing flat plate height of the dragline shovel will result in both efficiency improvements and efficiency reductions, and the overall efficiency change of the system is difficult to predict. However, the operational logic of the overcast stripping system is complex, and there are a large number of random and fuzzy factors. Thus, it is difficult to use conventional optimization methods to determine the optimal working face parameters.

\section{System Simulation Method}

3.1. Simulation Optimization Solution Ideas and Steps. In view of the complex internal logical structure of the dragline stripping technology, the interrelation between each process and each level, and the limitations of conventional system modeling, the optimal solution cannot be obtained. Thus, a system optimization method is proposed. The core idea and main steps of the proposed method are as follows: 


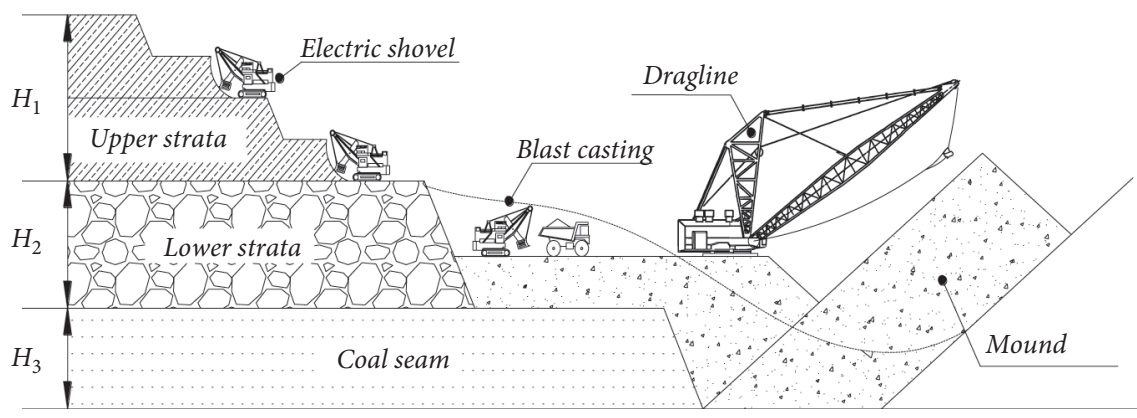

FIgURE 1: Profile of stope with overcast stripping technology.

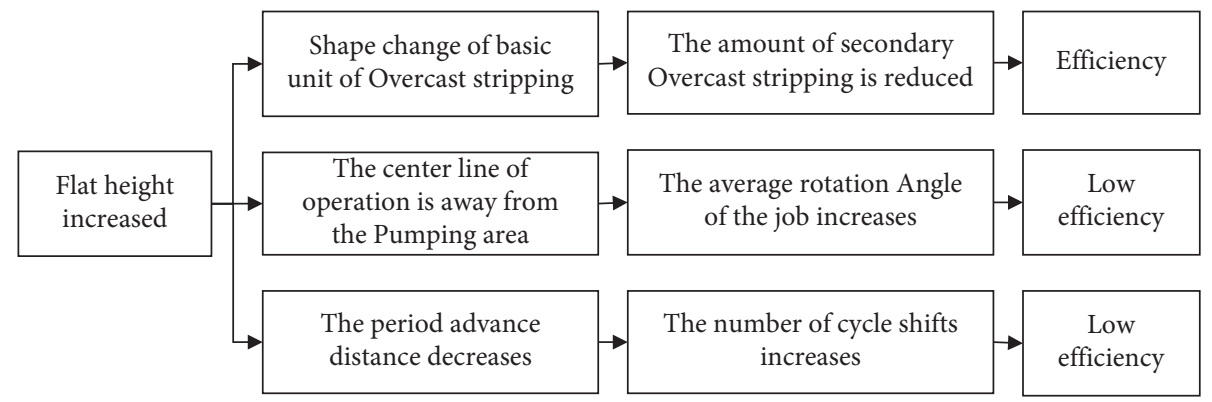

FIGURE 2: Influence of step height variation on system efficiency.

Step 1. According to the random and fuzzy production characteristics of the dragline stripping technology, a reasonable system simulation model and method are selected.

Step 2. Detailed analysis of the dragline stripping technology elements is carried out to identify all levels, links, and relationships within the system. This allows the system simulation modeling elements to be identified and the events driving the extraction system to be determined.

Step 3. A digital model of the production process of the dragline stripping technology is constructed according to the production factors and their mutual relations with the dragline stripping technology. However, considering the complex internal structure of the dragline stripping technology, the system simulation model needs to be simplified to improve the efficiency of system simulation.

Step 4. In the process of system simulation, all internal elements change dynamically. To accurately simulate the changes in all elements, it is necessary to further build a system state model, quantify the system states under different conditions, and effectively control the system states based on engineering practice.

Step 5. System simulations are implemented, and the system operation process is repeated with various parameter combinations to obtain decision-making information.

\subsection{System Simulation Model Types and System Simulation Methods}

3.2.1. System Simulation Models. Simulation models can be either continuous or discrete. In the former, the system state changes continuously with time, whereas in the latter, changes to the system state are driven by random events. The ultimate goal of the simulation is to investigate the system efficiency under different working face parameters, that is, to optimize the design scheme so that the same tasks can be completed in the shortest time. Therefore, the time consumption of each basic operation in the system can be regarded as the lowest random event in the simulation process, and this is the construction objective of the quantization model of discrete events. The operation logic of the system constitutes a discrete event system, which is driven by random events and should be described by a discrete event system simulation model [21].

3.2.2. Clock Advance Method. Discrete events are simulated in a process-oriented way and executed in an event-oriented way. Therefore, a timing variable needs to be set to record the occurrence time of a certain low-level random event [22]. In the simulation of a clock advancing during overcast stripping, the time step method calculates the probability of new events occurring at each moment, while the event step method only calculates the probability of current events taking a certain amount of time. Thus, the event step method should be used to advance the analog clock to simplify the calculation scheme. 
3.3. System Production Process Analysis and Deconstruction. In the overcast stripping production system, the material migrates from the work area to the pumping area under the external action of the dragline. The overcast stripping working face, the mound, and the dragline equipment constitute the main elements of the system. From the stope structure, the working face can be divided into many parts, and the shape of each part is extremely irregular (as shown in Figure 3), leading to large fluctuations in operational efficiency of different items of equipment. In terms of the equipment operation process, different machine positions may have the dragline at the advanced ditch, discharging coal ditch material to the mound. In addition, there is a strict sequence regarding digging and discharging [23]. Therefore, at every moment of system operation, the geometry of the working face and the mound, the position of the dragline, and the position of material excavation affect the system state. The positions of the dragline and material excavation are specified by operation rules, and can therefore be described by system control logic. The geometry of the working face and mound are subject to passive changes in the system and can only be determined through quantitative calculations using the system state model.

Analysis of the system characteristics indicates that there are three levels of logical flow in the process of overcast stripping:

(1) Place the dragline in a specific machine position.

(2) When the dragline is in a certain machine position, excavate materials in different areas in turn (as shown in Figure 4(a)).

(3) In one operation cycle, repeat the dragline maneuvering actions in a certain order (as shown in Figure 4(b)).

3.4. Digital Model of System Production Process. In essence, overcast stripping is the operation of moving a large amount of earth and stone. The changes in the material storage space of the working face and pumping area define the whole system process. Suppose that, at any time, the operating state of the system is described by a group of state variables, namely,

$$
X=\left(x_{1}, x_{2}, \ldots, x_{i}, \ldots x_{n}\right)^{T},
$$

where $X$ is the state vector and $x_{i}$ is the state variable, $i=1,2$, $\ldots, n$, during the operation of the system. Different state vectors $X$ form a point in the storage state space $R^{n}$. To realize the orderly state transition of the system in the process of simulation, it is necessary to exert more control on the system. Let the system control vector be

$$
U=\left(u_{1}, u_{2}, \ldots, u_{r}\right)^{T} .
$$

According to the state vector and control vector, the triplet $\left[X_{s}, C(U), X_{g}\right][24]$ of the system state space can be constructed, where $X_{s}$ is the initial state vector and $X_{g}$ is the target state vector, describing the storage space state of materials between the working face and the dump before and after the system simulation. $C(U)$ refers to the state transfer operation generated by $u$ and represents the control logic of the system. This expresses the procedural and control knowledge of the system transfer and is determined by the basic operation process.

3.4.1. Barycentric Circular Projection Model of Material Migration. Practical engineering problems are often complex. To enable effective system analysis and synthesis, it is necessary to simplify the problem. In this case, simplification enables the system control logic (i.e., digging position, abandoning position, and overcast stripping track of the dragline) and the system state space (i.e., working face and pumping area of material storage space) to be modeled.

During digging operations, the dragline is usually pushed into the soil and rock for $5-20 \mathrm{~m}$ to complete the material loading process. Therefore, the original distribution of the material in each bucket is a strip on the line segment from the operational center point of the dragline along its operational radius. The material on the line segment is generally discarded in the same position; that is, the operational rotation angle of the material on each line segment is the same. Therefore, we establish $m$ center points passing through the dragline operation position that are perpendicular to the horizontal plane $\left\{S_{1}, S_{2}, \ldots, S_{m}\right\}$. Let $W_{i}$ represent the overcast stripping by cutting the surface joining $S_{i}$ to $S_{i+1}$; this is the basic unit of the cutting face and is projected onto a circle with radius $R$. Similarly, the mound is cut and its spatial capacity is projected onto the circle. When the rays are dense enough, the rotation angles of all materials in the same block can be regarded as the same, thus establishing the gravity circle projection model of the backfill operation (as shown in Figure 5).

The barycentric circular projection model can be described by a directed graph system considering the singleloop transportation of the overcast stripping system (each rotation of the body is no more than $180^{\circ}$ ). Taking $W_{i}$ as the starting point and $P_{j}$ as the end point in Figure 5, $D=(V, A)$ is a simple graph without loops:

$$
\begin{aligned}
& V=\left\{w_{1}, w_{2}, \ldots, w_{i}, \ldots, w_{m}, p_{1}, p_{2}, \ldots, p_{j}, \ldots, p_{m}\right\} \\
& A=\left\{w_{1} p_{j_{1}}, w_{2} p_{j_{2}}, \ldots, w_{i} p_{j_{i}}, \ldots, w_{m} p_{j_{m}}\right\}, j_{i} \in\{1,2, \ldots, m\}, j_{1} \neq j_{2} \neq \ldots \neq j_{m} .
\end{aligned}
$$




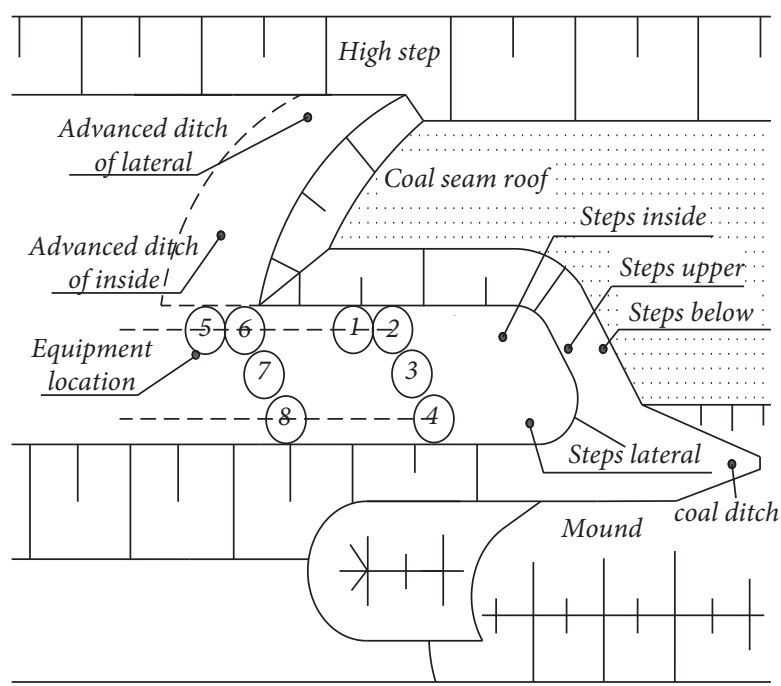

(a)

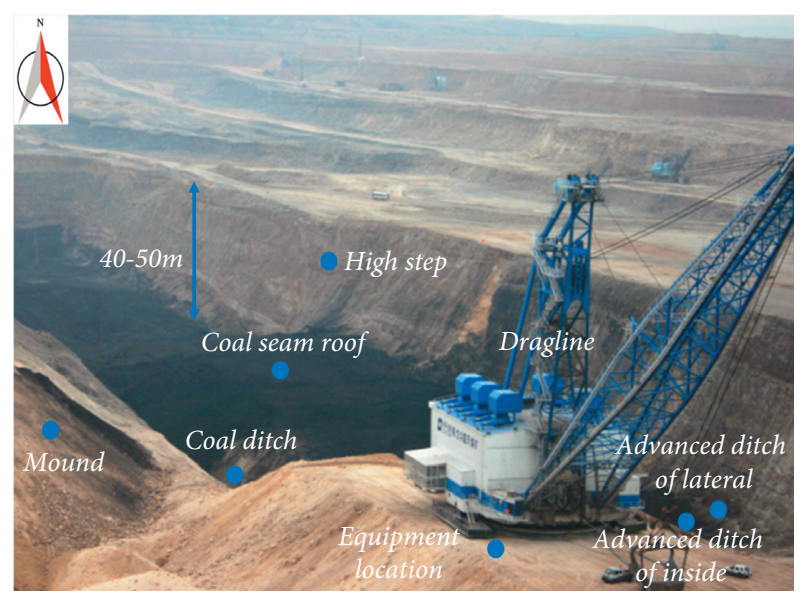

(b)

FIgURE 3: Working surface diagram of overcast stripping technology: (a) planar graph; (b) construction plan.

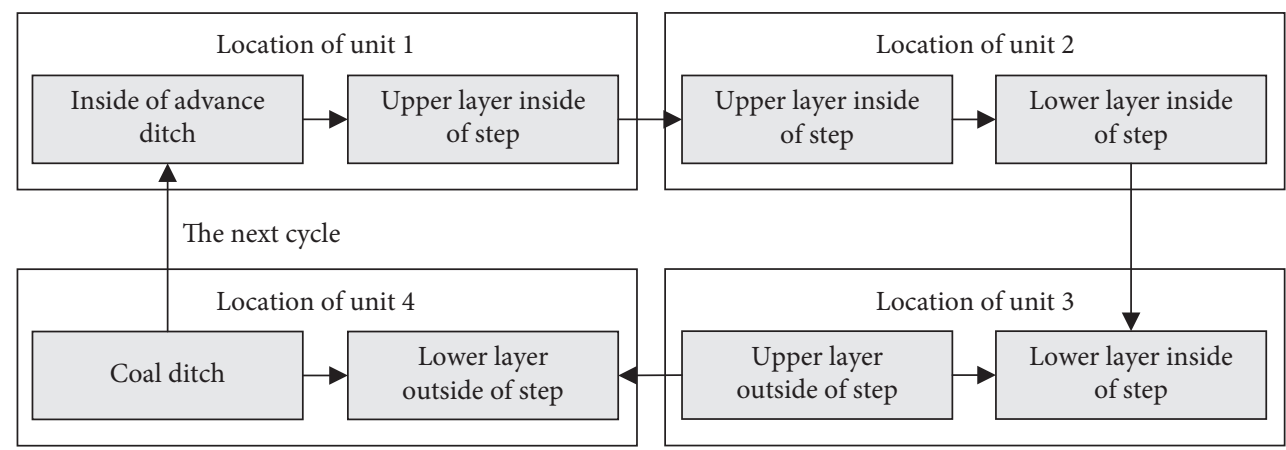

(a)

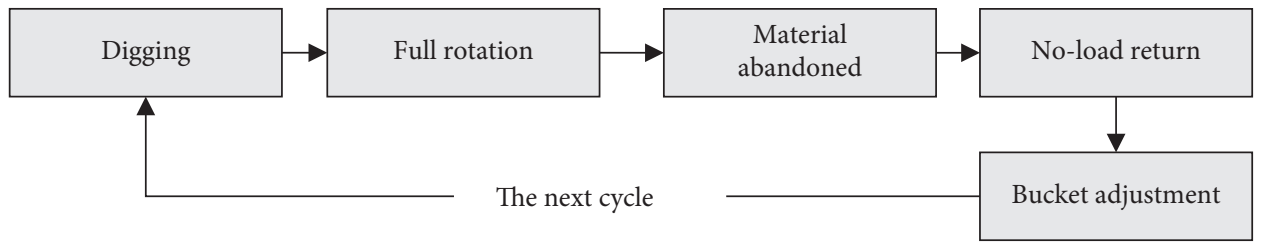

(b)

FIgURE 4: System logic flow diagram: (a) first and second layers of logic flow; (b) third layer of logic flow.

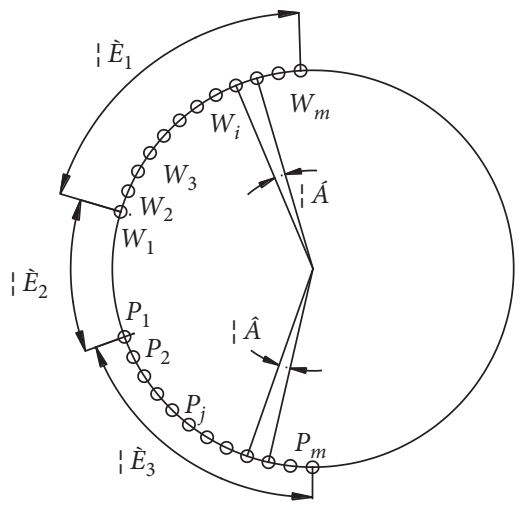

Figure 5: Digraph of single wing waste with excavation and dumping. 
In Figure 5, $\left\{W_{1}, W_{2}, \ldots, W_{m}\right\}$ represents the shovel dig point; $\left\{P_{1}, P_{2}, \ldots, P_{m}\right\}$ represents the abandonment point of the dragline shovel; $\theta 1$ represents the total angle of the excavator area; $\theta_{2}$ represents the total angle from the excavation area to the dumping area of the dragline shovel; $\theta_{3}$ represents the total angle of the dumping area of the dragline shovel; $\alpha$ represents the angle between the dig sites; and $\beta$ represents the angle between discard points.

We denote the material volume and internal row capacity as $W$, and the material capacity of each node as the single transport volume $\mathrm{W} / \mathrm{m}$ of the equipment. Then, the arc capacity $C\left(W_{i}, P_{j}\right)$ is $W / m$, and the degree of the node $d_{G}=\left(W_{i}\right)=d_{G}=\left(P_{j}\right)=1$. The angular interval of material nodes in the mining area is $\alpha$, and the central angle of the fan-shaped area formed on the center of the gravity circle is $\theta_{1}$. The angular interval of the nodes in the abandoned region is $\beta$, and the central angle of the region is $\theta_{3}$. The central angle of excavation and discarding in the middle area is $\theta_{2}$, and so the total rotation angle $\Psi$ of single-ring operation is

$$
\begin{aligned}
\psi & =\sum_{i=1}^{m}(i-1) \alpha+\sum_{j=1}^{m}(j-1) \beta+m \theta_{2} \\
& =m\left[\left(\frac{\theta_{1}+\theta_{3}}{2}\right)+\theta_{2}\right] .
\end{aligned}
$$

According to (4), when the size and location of the material in the working face and the space of the dump are determined, the total rotation angle $\Psi$ of the material is a constant value.

3.4.2. Optimization of System Control Logic. The relationship $y=F(\eta)$ between the time consuming and the rotation angle of the material transportation link (full load rotation, no load return) is nonlinear with respect to time. According to a large number of statistical results, $F(\eta)$ is a concave function, so it is necessary to discuss the influence of different material transfer sequences and paths on the total time $B=\sum_{i=1}^{m} F\left(\eta_{i}\right)$. Let $m=\left\{\eta_{1}, \eta_{2}, \ldots, \eta_{m}\right\}, \quad \theta_{2} \leq \eta_{1} \leq$ $\eta_{2} \leq \ldots \quad \leq \eta_{m} \leq \theta_{1}+\theta_{2}+\theta_{3}, \quad \sum_{i=1}^{m} \eta_{i}=m\left[\left(\theta_{1}+\theta_{3} / 2\right)+\theta_{2}\right]$. Assume that $\eta_{1}, \eta_{1}^{\prime}, \eta_{2}, \eta_{2}^{\prime} \in\left[\theta_{2}, \theta_{1}+\theta_{2}+\theta_{3}\right], \eta_{1}^{\prime}+\eta_{2}^{\prime}=\eta_{1}+$ $\eta_{2}$, and $\eta_{2}^{\prime}>\eta_{2} \geq \eta_{1}>\eta_{2}^{\prime}$. According to the mean value theorem, there is some $\xi_{1} \in\left(\eta_{1}^{\prime}, \eta_{1}\right), \xi_{2} \in\left(\eta_{2}, \eta_{2}^{\prime}\right)$ such that

$$
\begin{aligned}
& F\left(\eta_{1}\right)-F\left(\eta_{1}^{\prime}\right)=F^{\prime}\left(\xi_{1}\right)\left(\eta_{1}-\eta_{1}^{\prime}\right), \\
& F\left(\eta_{2}^{\prime}\right)-F\left(\eta_{2}\right)=F^{\prime}\left(\xi_{2}\right)\left(\eta_{2}^{\prime}-\eta_{2}\right) .
\end{aligned}
$$

As $F(\eta)$ is a strictly concave function, $F^{\prime}(\eta)$ decreases monotonically on $[a, b]$, i.e., $F^{\prime}\left(\xi_{2}\right)-F^{\prime}\left(\xi_{1}\right)<0$ :

$$
\begin{aligned}
F( & \left.\eta_{1}^{\prime}\right)+F\left(\eta_{2}^{\prime}\right)-F\left(\eta_{1}\right)-F\left(\eta_{2}\right) \\
& =\left[F^{\prime}\left(\eta_{2}^{\prime}\right)-F\left(\eta_{2}\right)\right]-\left[F\left(\eta_{1}\right)-F\left(\eta_{1}^{\prime}\right)\right] \\
& =F^{\prime}\left(\xi_{2}\right)\left(\eta_{2}^{\prime}-\eta_{2}\right)-F^{\prime}\left(\xi_{1}\right)\left(\eta_{1}-\eta_{1}^{\prime}\right) \\
& =\left[F^{\prime}\left(\xi_{2}\right)-F^{\prime}\left(\xi_{1}\right)\right]\left(\eta_{1}-\eta_{1}^{\prime}\right)<0 .
\end{aligned}
$$

With $\eta_{1}+\eta_{2}$ being a fixed value, when $\left|\eta_{1}-\eta_{2}\right|$ increases, $F\left(\eta_{1}\right)+F\left(\eta_{2}\right)$ decreases. Thus, in general, we have

$$
\begin{aligned}
& B=m F\left(\frac{1}{m} \sum_{i=1}^{m} \eta_{i}\right), \\
& B \geq \sum_{i=1}^{m} F\left(\eta_{i}\right) \geq \frac{m}{2}\left[F\left(\theta_{2}\right)+F\left(\theta_{1}+\theta_{2}+\theta_{3}\right)\right] .
\end{aligned}
$$

That is, "gap discarding" (i.e., the distribution of a single rotation angle tends to the maximum and minimum values of the defined domain) gives the lowest total transport time. Considering practical problems, the order of excavation and discarding at each node can be obtained from

$$
\operatorname{Min} B=\operatorname{Min}\left[\sum_{i=1}^{m} F\left(\eta_{i}\right)\right]=\sum_{i=0}^{m-1} F\left[\theta_{2}+i \times(\alpha+\beta)\right] .
$$

Therefore, the materials at point $W_{i}$ in Figure 5 will be discarded at point $P_{j}$.

\subsection{System State Model}

3.5.1. 3D Simulation Model of Basic Operation Unit. In the simulations, the variations in the material storage space of the working face and pumping area must be quantitatively calculated to identify the dynamic changes between the two and build the system state model. However, the overcast stripping of the basic unit in the initial and final simulation states is not regular, and the conventional planar graphic method cannot calculate the material space and volume. Therefore, it is necessary to build a 3D simulation model of the basic unit of the overcast stripping system (as shown in Figure 6) and provide a quantitative basis for the construction of the system state model. The model building process is outlined below:

(1) The size of the upper top surface of the advance ditch unit can be directly obtained by a planar drawing. The slope angles of high step and the step angles of the dragline operation are $65^{\circ}$ and $38^{\circ}$, respectively. The arc surface formed by bucket cutting is simplified into an inclined plane with a natural repose angle of $38^{\circ}$, so as to construct the advance ditch unit.

(2) The geometric shape of the lower part of the step element body is relatively complex. In this study, Boolean calculations are applied to the established units of the advance ditch, coal seam, and mound, and a 3D model of the step element body is formed after cutting.

(3) The unit body of the mound is formed by the sequential accumulation of materials at multiple operation sites. Iterative modeling is applied until the volume and position of the mound are stable and have a certain periodicity, giving the real form of the actual mound.

(4) According to the center of gravity circular projection model, block cutting and projection are applied to pull the dragline operation rotation center to the center of the circle in the constructed 3D model. The 


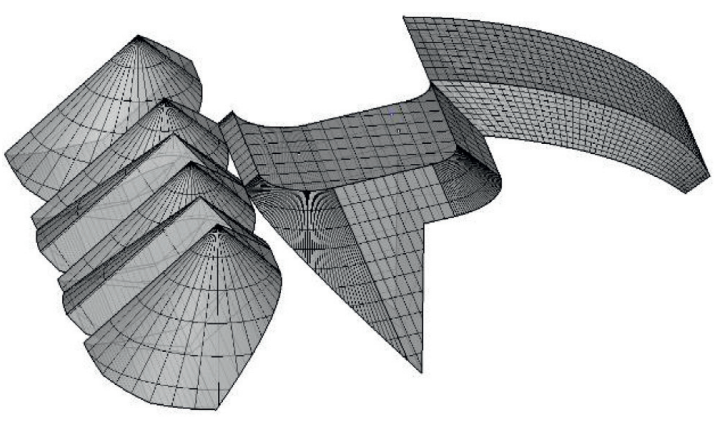

(a)

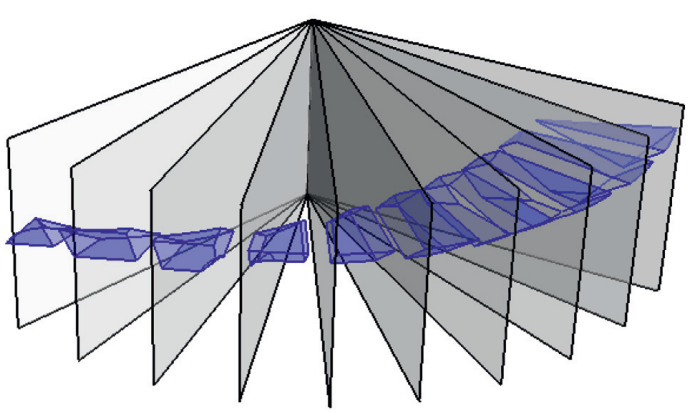

(b)

FIGURE 6: 3D modeling of elementary operating unit: (a) unit block model; (b) block cutting method diagram.

included angle of each section is $5^{\circ}$. Thus, the spatial positions of the volume and center of gravity of the unit block of the working face after cutting are obtained (as shown in Figure 6(b)). The corresponding abandonment position of each cut block is then determined using the optimized excavation-abandonment rule.

Note that, in the process of 3D model construction, key issues such as the size of the basic unit, upper and lower layer division, Boolean operation principle, and cutting position are closely related to the equipment operation characteristics and operation mode. For detailed modeling methods and principles, please refer to [25-28].

3.5.2. System State Model. The system state model is constructed according to the barycentric circular projection model:

$$
X=\left(w_{1}, w_{2}, \ldots, w_{i}, \ldots, w_{m}, p_{1}, p_{2}, \ldots, p_{j}, \ldots, p_{m}\right)^{T},
$$

where $w_{i}$ and $p_{j}$ are state variables, $w_{i}$ represents the current remaining material amount of block $i$ after cutting the basic unit of the working face, and $p_{j}$ represents the current material storage of the corresponding abandoned position of block $i$.

Obviously, the initial state vector of the system is

$$
X_{s}=\left(w_{1}, w_{2}, \ldots, w_{i}, \ldots, w_{m}, 0,0, \ldots, 0\right)^{T},
$$

and the system target state vector is

$$
X_{g}=\left(0,0, \ldots, 0, w_{1}, w_{2}, \ldots, w_{i}, \ldots, w_{m}\right)^{T} .
$$

The basic unit of the system state change is the material in a single bucket. Thus, we set an operation cycle to dump a bucket of material from block $i$ of the working face to abandonment point $i$. The control vector of the system is

$$
U=(0,0, \ldots,-u, \ldots, 0, \ldots, u, \ldots, 0)^{T},
$$

whereby the system state changes to

$$
X^{\prime}=X+U=\left(w_{1}, w_{2}, \ldots, w_{i}-u, \ldots, w_{m}, p_{1}, p_{2}, \ldots, p_{j}+u, \ldots, p_{m}\right)^{T}
$$

The system state vector is transformed from $X_{s}$ to $X_{g}$, and the number of transitions is

$$
n=\sum_{i=1}^{m} \frac{w_{i}}{u}
$$

The average time required for a state change (the average time of the underlying driver event loop) is

$$
\bar{t}=\frac{t}{n} \text {. }
$$

The operating efficiency of the equipment is

$$
E=\sum_{i=1}^{m} \frac{w_{i}}{t}
$$

where $t$ is the system operation time, which is recorded by the timing variable.
3.6. System Simulation Model Construction and Implementation. For discrete events, the average index of statistical data does not always reflect the regularity of actual production conditions. Therefore, it is necessary to build a probability distribution model for the lowest level of random events and then reproduce the temporal regularity of random events through a random number generator to restore the actual operation conditions as realistically as possible. On this basis, the timing variable plus the corresponding event time are used to determine the time of the next event in the simulation process.

Analysis of the system characteristics indicates that the time required for digging and bucket adjustment is related to the digging position, while the time required for bucket rotation is related to the digging position and the rotation angle. Therefore, for the digging and bucket adjustment links, the probability distribution function is $P\left(A_{i}, L_{i}\right)$, 
whereas for the rotation links, the probability distribution function is $P\left(A_{i}, \theta, L_{i}\right)$. Once the system simulation model has been constructed, the system simulation enters the implementation stage.

Figure 7 shows a flowchart of the simulation calculations, where $\theta$ is the rotation angle of equipment operation; $A_{i}(i=1,2, \ldots, 7)$ represents the different excavation positions (inside of advance ditch, outside of advance ditch, upper layer inside of step, lower layer inside of step, upper layer outside of step, lower layer outside of step, coal ditch); and $L_{i}(i=1,2, \ldots, 5)$ represents different operation procedures (digging, full load rotation, discharge, no-load return, bucket adjustment).

Obviously, the dragline stripping technology is relatively complex, making it very difficult to solve the model directly. Analysis of this complex process and the characteristics and relationships of each link has led to the establishment of a quantitative model of the process. In this model, each link behaves according to experimental or quantitative analysis, and specific and detailed information is required to obtain suitable decisions.

\section{System Simulation Results}

Long-term data collection indicates that the temporal distribution of each facet of dragline mining is as shown in Figures $8-12$. The probability distribution functions of the operation time were established on this basis $[29,30]$, and the results are presented in Table 1 for the example of a full load rotation link. During the simulations, the different functions in Table 1 are called according to the system logic.

We simulated the operation of the dragline in one cycle under working flat plate heights of $11-15 \mathrm{~m}$ and a full bucket coefficient of 0.75 . The calculation results are presented in Tables 2 and 3.

The simulation results show the following:

(1) When the step height rises from $11 \mathrm{~m}$ to $15 \mathrm{~m}$, the operation rotation angle decreases at first and then increases. However, the rotation angle has little influence on the average time of the rotation link.

(2) The adjustment time is the main factor affecting the average time of an operation cycle. This is because, as the step height changes, the initial state of the material distribution in the working face changes. Additionally, with a $15 \mathrm{~m}$ bench height, the materials in the coal groove reach a total of $29969 \mathrm{~m}^{3}$, nearly double that with an $11 \mathrm{~m}$ bench height. The average time required to adjust the bucket in these two areas is $7-8 \mathrm{~s}$, whereas the average adjustment time in other areas is only $\sim 4 \mathrm{~s}$.

(3) When the dragline height of the scraper is around $13 \mathrm{~m}$, the operating efficiency of the equipment reaches a maximum of $4276.52 \mathrm{~m}^{3} / \mathrm{h}$. According to field data from Heidaigou open-pit mine, the production capacity of the scraper reaches a maximum of $4026 \mathrm{~m}^{3} / \mathrm{h}$ when the flatbed height is $13.3 \mathrm{~m}$ [31]. The simulation results for the operating efficiency are therefore consistent with the actual situation.

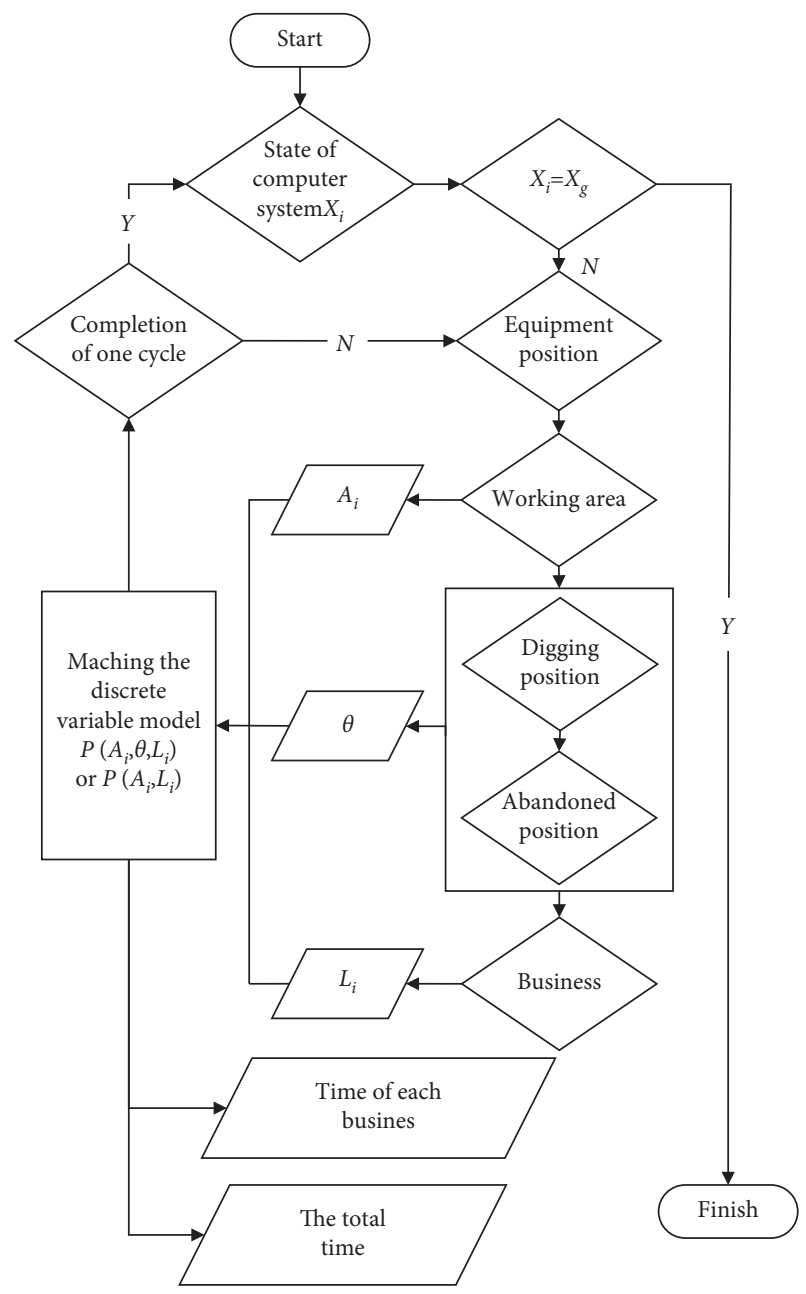

FIGURE 7: Simulation calculation flowchart.

\section{Discussion and Analysis of Results}

For the overcast stripping system, the flatbed height is an extremely important parameter in the dragline operation. Therefore, this study simulated the one-cycle operation of the dragline under working flat plate heights of $11-15 \mathrm{~m}$. The simulation results in Tables 2 and 3, combined with the production characteristics of the overcast stripping system, can be analyzed as follows:

(1) When the number of bulldozers and the scale of the single-bucket-truck auxiliary dragline operation are reduced, the layered advance speed on the cast blasting stockpile accelerates. Simultaneously, the step advance speed of the dragline operation decreases, the coal seam advance speed is reduced, the overall stripping cost of the system is reduced, and the raw coal output is limited.

(2) As the width of the operation steps decreases, the basic unit shape of the dragline operation changes, and the scale of the secondary dragline operation decreases. Thus, the amount of material in the coal ditch decreases, and the total system output decreases. 


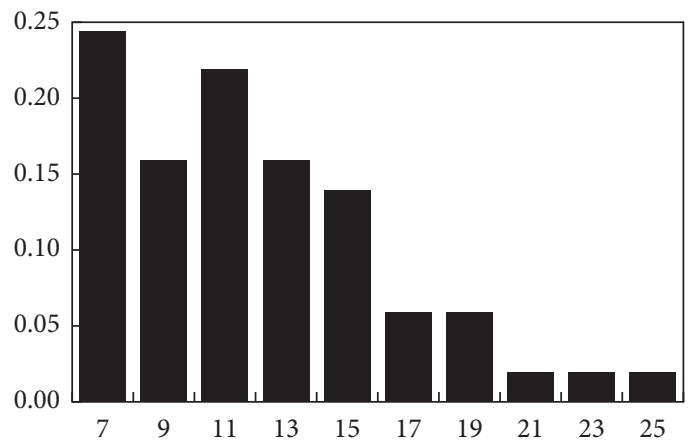

Figure 8: Frequency distribution histogram of coal ditch excavation.

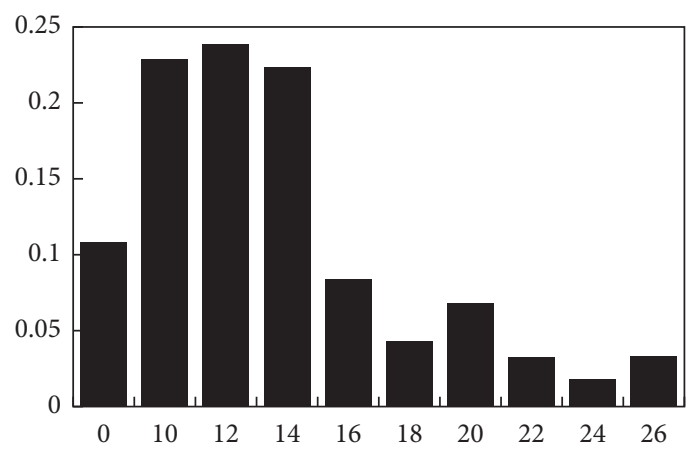

FIGURE 9: Frequency distribution histogram of bench excavation (lower slice).

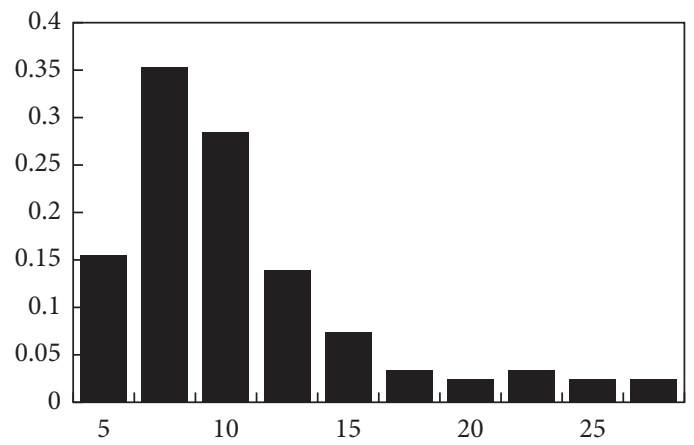

FIGURE 10: Frequency distribution histogram of bench excavation (upward slice).

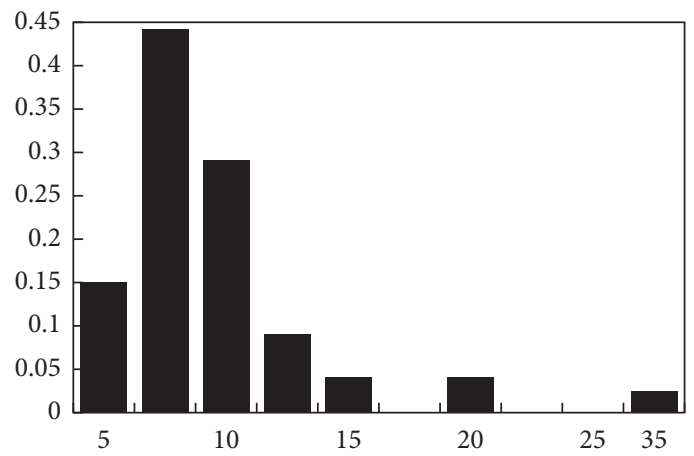

FIGURE 11: Frequency distribution histogram of advanced ditch excavation (inner side). 


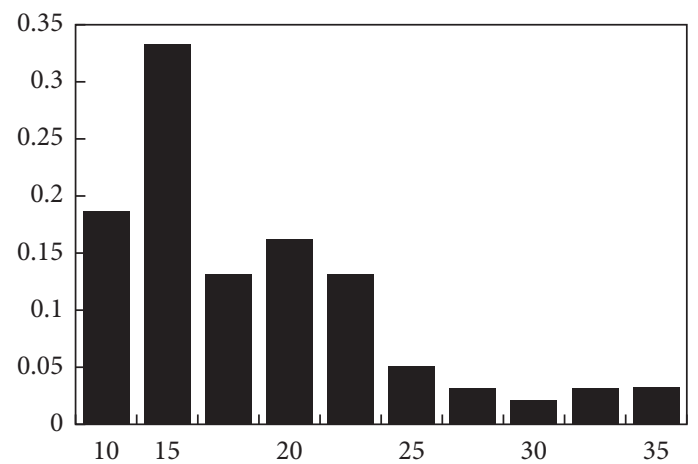

Figure 12: Frequency distribution histogram of advanced ditch excavation (outside).

TAвLE 1: Fitting functions for probability distributions of time consumption (full load swing step).

\begin{tabular}{llc}
\hline Range of rotation angle & Distribution form & Fitting function \\
\hline $70-80^{\circ}$ & Normal distribution & $f(x)=(1 / \sqrt{2 \pi}) e^{-(x-\mu)^{2} / 2 \sigma^{2}}, \mu=22.85, \sigma=2.61$ \\
$80-90^{\circ}$ & Gamma distribution & $f(x)=\left(1 / \beta^{\alpha} \Gamma(\alpha)\right) x^{\alpha-1} e^{-x / \beta}, \alpha=148.48, \beta=0.16$ \\
$90-100^{\circ}$ & Gamma distribution & $f(x)=\left(1 / \beta^{\alpha} \Gamma(\alpha)\right) x^{\alpha-1} e^{-x / \beta}, \alpha=105.26, \beta=0.24$ \\
$100-110^{\circ}$ & Poisson distribution & $f(x)=\left(1 / \beta^{\alpha} \Gamma(\alpha)\right) x^{\alpha-1} e^{-x / \beta}, \alpha=91.79, \beta=0.28$ \\
$110-120^{\circ}$ & Gamma distribution & $f(x)=\left(1 / \beta^{\alpha} \Gamma(\alpha)\right) x^{\alpha-1} e^{-x / \beta}, \alpha=69.89 \beta=0.39$ \\
$120-130^{\circ}$ & Normal distribution & $f(x)=(1 / \sqrt{2 \pi}) e^{-(x-\mu)^{2} / 2 \sigma^{2}}, \mu=30.24, \sigma=3.02$ \\
$130-140^{\circ}$ & Gamma distribution & $f(x)=\left(1 / \beta^{\alpha} \Gamma(\alpha)\right) x^{\alpha-1} e^{-x / \beta}, \alpha=114.56, \beta=0.27$ \\
$140-150^{\circ}$ & Normal distribution & $f(x)=(1 / \sqrt{2 \pi}) e^{-(x-\mu)^{2} / 2 \sigma^{2}}, \mu=30.42, \sigma=4.30$ \\
\hline
\end{tabular}

TABLE 2: Operational efficiency under various bench heights.

\begin{tabular}{|c|c|c|c|c|c|c|c|c|}
\hline & Step height $(\mathrm{m})$ & $\begin{array}{c}\text { Advanced } \\
\text { ditch }\end{array}$ & Step & $\begin{array}{l}\text { Coal } \\
\text { ditch }\end{array}$ & $\begin{array}{l}\text { Total } \\
\text { time }\end{array}$ & $\begin{array}{l}\text { Efficiency }\left(\mathrm{m}^{3} /\right. \\
\mathrm{h})\end{array}$ & $\begin{array}{l}\text { Efficiency }\left(\mathrm{m}^{3} /\right. \\
\text { a) }\end{array}$ & $\begin{array}{l}\text { Efficiency change (compared to } \\
11 \mathrm{~m} \text { step) }\end{array}$ \\
\hline \multirow[b]{2}{*}{11} & $\begin{array}{c}\text { Material volume } \\
\qquad\left(\mathrm{m}^{3}\right)\end{array}$ & 35647 & 68110 & 3654 & 107410 & \multirow[b]{2}{*}{4249.54} & \multirow[b]{2}{*}{19122930} & \multirow[b]{2}{*}{0} \\
\hline & $\begin{array}{c}\text { Time consumption } \\
(\mathrm{h})\end{array}$ & 10.09 & 14.19 & 0.98 & 25.11 & & & \\
\hline \multirow{2}{*}{12} & $\begin{array}{c}\text { Material volume } \\
\left(\mathrm{m}^{3}\right)\end{array}$ & 37312 & 68204 & 4318 & 109833 & \multirow{2}{*}{4264.21} & \multirow{2}{*}{19188945} & \multirow{2}{*}{$+0.35 \%$} \\
\hline & $\begin{array}{c}\text { Time consumption } \\
(\mathrm{h})\end{array}$ & 10.44 & 14.24 & 1.08 & 25.76 & & & \\
\hline \multirow{2}{*}{13} & $\begin{array}{l}\text { Material volume } \\
\left(\mathrm{m}^{3}\right)\end{array}$ & 38769 & 67638 & 5081 & 111489 & \multirow{2}{*}{4276.52} & \multirow{2}{*}{19244340} & \multirow{2}{*}{$+0.63 \%$} \\
\hline & $\begin{array}{l}\text { Time consumption } \\
(\mathrm{h})\end{array}$ & 10.75 & 14.08 & 1.24 & 26.07 & & & \\
\hline \multirow[b]{2}{*}{14} & $\begin{array}{l}\text { Material volume } \\
\qquad\left(\mathrm{m}^{3}\right)\end{array}$ & 40042 & 66237 & 5815 & 112063 & \multirow[b]{2}{*}{4269.49} & \multirow[b]{2}{*}{19212705} & \multirow[b]{2}{*}{$+0.47 \%$} \\
\hline & $\begin{array}{l}\text { Time consumption } \\
(\mathrm{h})\end{array}$ & 10.99 & 13.97 & 1.32 & 26.28 & & & \\
\hline \multirow{2}{*}{15} & $\begin{array}{c}\text { Material volume } \\
\left(\mathrm{m}^{3}\right)\end{array}$ & 41146 & 63882 & 6705 & 111690 & \multirow{2}{*}{4165.98} & \multirow{2}{*}{18746910} & \multirow{2}{*}{$-1.97 \%$} \\
\hline & $\begin{array}{c}\text { Time consumption } \\
(\mathrm{h})\end{array}$ & 11.38 & 13.82 & 1.61 & 26.81 & & & \\
\hline
\end{tabular}

TABLE 3: Operational efficiency under various operation links.

\begin{tabular}{|c|c|c|c|c|c|c|c|c|}
\hline $\begin{array}{l}\text { Step } \\
\text { height } \\
\text { (m) }\end{array}$ & $\begin{array}{l}\text { Corresponding } \\
\text { step width }(\mathrm{m})\end{array}$ & $\begin{array}{c}\text { Number of } \\
\text { digging } \\
\text { operations }\end{array}$ & $\begin{array}{l}\text { Average } \\
\text { rotation } \\
\text { angle }\left({ }^{\circ}\right)\end{array}$ & $\begin{array}{l}\text { Average } \\
\text { digging } \\
\text { time (s) }\end{array}$ & $\begin{array}{c}\text { Adjusted } \\
\text { average time } \\
\text { (s) }\end{array}$ & $\begin{array}{l}\text { Mean time of } \\
\text { full load } \\
\text { rotation (s) }\end{array}$ & $\begin{array}{l}\text { Average no- } \\
\text { load return } \\
\text { time }(\mathrm{s})\end{array}$ & $\begin{array}{c}\text { Average } \\
\text { operation cycle } \\
\text { time }(\mathrm{s}) \\
\end{array}$ \\
\hline 11 & 139.8 & 1614 & 74.05 & 13.00 & 2.44 & 19.57 & 18.73 & 53.73 \\
\hline 12 & 133.5 & 1661 & 72.54 & 13.01 & 4.91 & 19.42 & 18.54 & 55.88 \\
\hline 13 & 127.9 & 1682 & 71.88 & 13.02 & 5.07 & 19.35 & 18.43 & 55.86 \\
\hline 14 & 122.9 & 1689 & 71.87 & 13.01 & 5.19 & 19.31 & 18.37 & 55.89 \\
\hline 15 & 117.6 & 1687 & 74.05 & 12.97 & 5.29 & 19.99 & 18.95 & 57.21 \\
\hline
\end{tabular}


TABLE 4: Error analysis and correction of simulation solutions.

\begin{tabular}{lccccc}
\hline Step height $(\mathrm{m})$ & Field test results $\left(\mathrm{m}^{3} / \mathrm{h}\right)$ & Simulation results $\left(\mathrm{m}^{3} / \mathrm{h}\right)$ & Error $(\%)$ & Simulation correction $\left(\mathrm{m}^{3} / \mathrm{h}\right)$ & Corrected error $(\%)$ \\
\hline 11 & 3941.40 & 4249.54 & 7.82 & 3994.57 & 1.35 \\
12 & 3999.72 & 4264.21 & 6.61 & 4008.36 & 0.22 \\
13 & 4024.88 & 4276.52 & 6.25 & 4019.93 & 0.12 \\
14 & 4016.88 & 4269.49 & 6.29 & 4013.32 & 0.09 \\
15 & 3975.70 & 4165.98 & 4.79 & 3916.02 & 1.50 \\
\hline
\end{tabular}

(3) When the center line of the dragline operation is far away from the pumping area, the average rotation angle of equipment operation increases, and the cycle time of one operation increases.

(4) When the dragline cycle advance distance decreases, the cycle advance time increases, and the time required to move equipment and move the shovel increases.

Error analysis of the simulation results is presented in Table 4. The conclusions are as follows:

(1) The simulation system is an abstract and idealized description of the actual system. However, there are a large number of uncontrollable factors in the actual system, and it is difficult to operate efficiently according to the standardized system logic process. Therefore, the simulation results are more efficient than the actual situation.

(2) During the actual operation of the overcast stripping system, the duration of each system state $X$ is discretely distributed, and its control vector $U$ is also discretely distributed. For example, in the process of equipment operation, the full bucket rate of each operation cycle should be a discrete event. However, in this study, the constant value of the full bucket coefficient was set to 0.75 based on experience. This will result in some errors.

(3) To improve the authenticity of the simulation process and the accuracy of the simulation solutions, the error sources can be considered comprehensively, and the simulation results can be corrected. The error can be greatly reduced when the correction coefficient $\alpha$ is set to 0.94 .

\section{Conclusion}

This paper has described an optimization method for the parameters of an open-pit mining system based on simulation technology. Quantitative analysis was performed by repeating the evolution of the system to obtain more accurate solutions.

The core ideas and simulation steps were established by focusing on dragline stripping technology. The components of the overcast stripping system were deconstructed, and the process flow of the system was determined. The events driving the system were also identified. A simplified simulation model and control logic were then constructed, and the dynamic laws of the simulation system were obtained. Finally, simulations of the system operation process were repeated to obtain decision-making information.
The Heidaigou open-pit mine overcast stripping system was selected as a specific case study. The logical process of the system was decomposed into three levels, and the basic operation links of the dragline were taken as the driving events of system. A barycentric circular projection method was proposed to simplify the control logic of the system. To accurately determine the dynamics of each element, a system storage state model was built to quantify the system state under different conditions. Finally, the discrete event system was modeled, whereby the simulation process was advanced by the event step method.

For the overcast stripping system, the flatbed height is a key parameter in the operation of the dragline. Therefore, this study simulated the operation of the dragline in one cycle under working flat plate heights of $11-15 \mathrm{~m}$. The simulation results show that the operating efficiency of the equipment is maximized when the working flat plate height of the dragline is around $13 \mathrm{~m}$. Error analysis of the simulation results found that a correction coefficient of $\alpha=0.94$ significantly reduces the modeling error.

\section{Data Availability}

The basic data involved in this study were obtained by the author and the production site of Heidaigou open-pit coal mine for a long time.

\section{Conflicts of Interest}

The authors declare no conflicts of interest.

\section{Acknowledgments}

The work was supported by the basic scientific research service fees of central universities (3142019007).

\section{References}

[1] Y. Ma, L. Wang, Da Zhang, and Xu Zhang, "Research on 3d visualization mining technology optimization of complex open-pit copper deposit," Nonferrous Metals (Mine), vol. 71, no. 4, pp. 1-4+18, 2019.

[2] F. Rui, "Optimization and practice of open-pit mining process for low grade copper and molybdenum ore," World Nonferrous Metals, vol. 11, pp. 227-228, 2021.

[3] Z. Song, D. Zhao, and Y. Zhang, "Open-pit coal mine in green mining process system optimization and process matching model," Journal of open-pit mining technology, vol. 35, no. 5, pp. 1-4, 2020.

[4] H. Zheng, Study on Comprehensive Process Optimization of Open-Pit Coal Mine under the Constraints of Complex 
Geological Structure and Multi-Rigid Process, China University of Mining and Technology, Xuzhou, China, 2021.

[5] J. Zhao, J. Sun, R. Bai et al., "Optimization of process Parameters of throwing blasting and pulling shovel dumping in Fault depression zone of Heidaigou Open-pit Coal Mine," Journal of coal, vol. 45, no. 10, pp. 3453-3461, 2020.

[6] L. Ma, J. Zhang, X. Lai et al., "Integrated process under the condition of the stripping of casting blast system working line length optimization," Journal of coal, vol. 46, no. 10, pp. 3186-3192, 2021.

[7] S. Xiao, X. Ding, Li Ma, and G. Dong, "Based on nonlinear programming of bucket shovel work platform parameter optimization," Journal of coal science, vol. 44, no. 10, pp. 3076-3084, 2019.

[8] S. Xiao, Research on Optimization Theory of Process Parameters of Throw Blasting and Dragline Shovel Dumping Pile, China University of Mining and Technology, Xuzhou, China, 2016.

[9] R. Liu, Research and Application of Engineering Optimization of Dragline Shovel and Dump Operation in Open-Pit Mine, North China learning institute of science and technology, Beijing China, 2020.

[10] S. Pervaiz, Z. Ul-Qayyum, W. H. Bangyal, L. Gao, and J. Ahmad, "A systematic literature review on particle swarm optimization techniques for medical diseases detection," Computational and Mathematical Methods in Medicine, vol. 2021, 2021.

[11] W. H. Bangyal, K. Nisar, A. A. B. Ibrahim, M. R. Haque, J. J. P. C. Rodrigues, and D. B. Rawat, "Comparative analysis of low discrepancy sequence-based initialization approaches using population-based algorithms for solving the global optimization problems," Applied Sciences, vol. 11, no. 16, p. $7591,2021$.

[12] W. H. Bangyal, J. Ahmad, and H. T. Rauf, "Optimization of neural network using improved bat algorithm for data classification," Journal of Medical Imaging and Health Informatics, vol. 9, no. 4, pp. 670-681, 2019.

[13] G. F. Sepúlveda, P. J. Álvarez, and J. B. Bedoya, "Stochastic optimization in mine planning scheduling," Computers \& Operations Research, vol. 115, Article ID 104823, 2020.

[14] M. Blom, A. R. Pearce, and P. J. Stuckey, "Short-term planning for open pit mines: a review," International Journal of Mining, Reclamation and Environment, vol. 33, no. 5, pp. 318-339, 2019.

[15] M. Rezakhah and A. Newman, "Open pit mine planning with degradation due to stockpiling," Computers \& Operations Research, vol. 115, Article ID 104589, 2020.

[16] R. Zhang, Y. Gao, H. Li, and X. Mei, "Optimization method of open-pit mining sequence and its applications[J]," Journal of China Coal Society, vol. 28, no. 5, pp. 491-495, 2003.

[17] R. Zhang and Y. Zhang, "A new approaeh to optimum decision-making of surface mining," Journal of China University of Mining \& Technology, vol. 23, no. 1, pp. 46-51, 994.

[18] C. Li and Y. Sun, "Optimizing big complex system of mining engineering by integrated artificial intelligence," Journal of Systems Engineering, vol. 17, no. 4, pp. 380-384, 2002.

[19] Y. Zhang and K. Li, Optimization Theory and Application of Surface Mining, pp. 18-28, China university of mining technology press, Xuzhou, 2000.

[20] Y. Zhang, "Development and prospect of mining systems engineering," Metal Mine, vol. 1, pp. 1-3, 2003.

[21] Z. Li, "Introduetion to diserete-event system simulation," Journal of System Simulation, vol. 1, pp. 21-30, 1989.
[22] L. Zhongxue, Z. Wenguang, and L. Cuiping, "Some recent advances in discrete event simulation and its applications," Computer Simulation, vol. 4, pp. 3-5, 1999.

[23] Y. Zhang and Y. Wang, Mining System Engineering, pp. 186-202, China university of mining technology press, Xuzhou, 2001.

[24] J. Sun, Research on System Optimization and Application of Dragline Stripping Technology in Surface Mine, China University of Mining and Technology, Beijing), 2016.

[25] X. Tu, c. Wang, and Y. Guo, Large System Cybernetics, pp. 36-40, Beijing University of Posts and Telecommunications Press, Beijing China, 2005.

[26] R. Zhang, J. Sun, X. Wen, X. Ma, and S. Zhang, "Research on dragline rational operation mode of Heidaigou surface mine," Coal engineering, vol. 48, no. 1, pp. 10-13, 2016.

[27] H. Chen, J. Sun, Y. Zhou, Y. Li, and H. Wu, "Design and analysis of dragline shifting engineering on working face," Coal Technology, vol. 47, no. 6, pp. 14-17, 2016.

[28] J. Sun, R. Zhang, H. Qiang, X. Ma, and H. Wu, "Research on appraisal standard with dragline operation technique," Coal Mine Machinery, vol. 47, no. 6, pp. 14-17, 2015.

[29] X. Ma and J. Sun, "Analysis on dragline rotation time-consuming and efficiency division," Coal Science and Technology, vol. 47, no. s1, pp. 51-54, 2015.

[30] J. Sun, "Analysis on dragline rotation time-consuming and efficiency division," Journal of Mining and Safety Engineering, vol. 04, pp. 721-727, 2016.

[31] P. Cheng and S. Xiao, "Determination of extended bench height of dragline in Heidaigou opencast coal mine," Coal engineering, vol. 47, no. 6, pp. 14-17, 2015. 